\title{
S.YU. WITTE'S VIEWS ON THE CULTURAL AND HISTORICAL SIGNIFICANCE OF THE RAILWAY COMMUNICATION IN THE EAST OF THE RUSSIAN EMPIRE
}

(C) 2019

Suvorov Valery Vladimirovich, candidate of historical sciences, researcher of History Museum

Saratov State Medical University named after V.I. Razumovsky (Saratov, Russian Federation)

Sulimin Aleksandr Nikolaevich, candidate of political sciences,

associate professor of History of State, Law and International Relations Department

Povolzhsky Institute of Management named after P.A. Stolypin - branch of The Russian Presidential Academy of National Economy and Public Administration (Saratov, Russian Federation)

\footnotetext{
Abstract. The paper presents the Minister of Finance S.Yu. Witte's views on cultural and historical significance of the railway communication in the Asian part of the Russian Empire. Although Witte primarily attached importance to the economic factor of the railroad, designed to connect the western and the eastern parts of Russia, he nevertheless often noted the military-strategic and cultural-historical significance of the Siberian railroad and the China Eastern Railway. Attaching particular importance to the railway communication in ensuring both economic and cultural contacts of Europeans, especially the population of Russia, with the Eastern peoples, Witte saw the «awakening» of the East and the expansion of its ties with the Western world as consequences. According to the Minister of Finance, such connections opened by the railway made it impossible to maintain alienation for the peoples of the Far East. Understanding the scale of the consequences of cultural, economic and political ties that had opened up, Witte noted a special task that was assigned to Russia in bringing Western and Eastern peoples closer together. Russia, providing the opportunity for interaction between the West and the East through the railway built by it, was to use, according to Witte, all the benefits of their convergence, which boiled down to the socio-economic and cultural development of Siberia and the Russian Far East. It is important that Witte also saw geopolitical changes associated with the possible rapprochement between Russia and Japan on the basis of common economic interests as a consequence of the development of the railway communication.

Keywords: Witte Sergei Yulyevich; Siberian railways; Chinese Eastern Railway; Russian empire; Siberia; Far East; West; East; Europe; Asia; Japan; China; Manchuria; rail service; industry; economic and cultural convergence; international trade.
}

$* * *$

УДК 94

DOI 10.24411/2309-4370-2019-14213

Статья поступила в редакцию 02.10 .2019

\section{СОЦИАЛ-ДАРВИНИСТСКАЯ ИДЕОЛОГИЯ ВО ВНУТРЕННЕЙ ПОЛИТИКЕ США НА РУБЕЖЕ XIX-XX ВЕКОВ}

(C) 2019

\author{
Мухатаев Павел Николаевич, учитель истории и обществознания \\ Гимназия № 133 г.о. Самара (2. Самара, Российская Федеращия)
}

\begin{abstract}
Аннотащия. В данной статье представлена попытка анализа взаимосвязи внутренней политики Соединенных Штатов Америки с социал-дарвинистской идеологией на рубеже XIX-XX вв. Советская и российская историография дает глубокий анализ социально-экономических и политических процессов данного периода с позиций критики либеральной идеологии и рыночной экономики. Сильное социальное расслоение объяснялось недостаточно развитой социально направленной законодательной базой, незаконным взаимодействием представителей крупного бизнеса и политиков, целью которых было личное обогащение и т.д. В целом, в российской историографии под критику попадала экономическая и политическая система США конца XIX начала XX века. В советской литературе делался вывод о несостоятельности «буржуазной идеологии», с элементами критики социал-дарвинизма как незначительной составляющей этой идеологии. У зарубежных авторов более многомерное представление о происходивших событиях. Зарубежная историография, как и советская, в основном анализирует связь внутренней политики с деятельностью финансовых магнатов, которые становятся новым серьезным игроком в американской политике. В данной статье предпринимается попытка выяснить наличие связи между внутренней политикой правительства Соединенных Штатов Америки и социалдарвинистским дискурсом, который был несомненной частью интеллектуальной и обыденной жизни граждан США данного исторического периода. Автор статьи указывает на существенное влияние социал-дарвинистской идеологии при принятии руководством Соединенных Штатов ключевых внутриполитических решений.

Ключевые слова: социал-дарвинизм; внутренняя политика США конца XIX - начала XX века; Г. Спенсер; Э. Карнеги; Л. Уорд; У. Самнер; Г. Кливленд; Дж. Фиске; Г. Зинн; В.П. Мозолин; естественный закон; К. Фрик; А. Шлезингер; Дж. Брюэр; Ч. Кули; протекционизм; Р. Хофстедтер; laissez-faire.
\end{abstract}

Соединенные Штаты Америки на рубеже XIX$\mathrm{XX}$ вв. представляли собой довольно динамично развивающуюся страну с огромными человеческими, природными и финансовыми ресурсами. Однако социально-экономическое и политическое развитие го- сударства было наполнено борьбой противоборствующих мнений в интеллектуальных кругах, социальным напряжением, которое выплескивалось на улицы городов, настоящими войнами между предпринимателями разного уровня, обвинениями в корруп- 
ции крупных политиков и многими другими острыми столкновениями внутри американского общества.

Противоречия между мощнейшим экономическим рывком США и низким уровнем жизни основной массы населения страны должны были предполагать идеологическую базу, которую формировали политики, крупные бизнесмены, ученые и т.д. для объяснения социального «status quo».

В данной работе для нас особый интерес будут представлять идеологические конструкции, обосновывавшие социальное неравенство, экономическую политику государства, решение национального вопроса, внутриполитическую борьбу, политику в сфере образования в США. Нашей задачей станет анализ дискурсивных практик непосредственных участников социально-политической жизни, раскрытие связи между социал-дарвинистской риторикой и непосредственной внутренней политикой правительства Сoединенных Штатов Америки. Особую важность представляет дискурс, которым пользовались разные слои американского населения. Дискурсивные практики, как и язык, обусловливают некоторые особенности мышления, поведения, в том числе при принятии важных внутриполитических решений.

Конец XIX - начало XX в. в США - это время невероятного экономического бума, которое прекрасно описано в одном из томов советского четырехтомника по истории США. «Американский экспорт утроился, - говорится в работе, - количество обрабатываемой земли увеличилось с 70-х годов к началу нового века более чем в два раза, иммиграция в тот же период составила порядка 14 млн чел., стоимость промышленной продукции в указанный период увеличилась в три раза, в таком же темпе увеличилось количество рабочих, занятых в промышленности» $[1$, c. 11-14]. Невероятные результаты экономического развития можно перечислять еще довольно долго, но нас интересует вопрос распределения экономических благ во всех социальных стратах и идеология, которая должна была удерживать всех участников событий на своих местах, а также легитимировать положение и деятельность властных структур.

Жизнь рабочих и фермеров не была столь оптимистичной, как цифры об экономических успехах государства в целом. Из-за цикличности развития рыночной экономики, которая к тому же не смягчалась в моменты кризисов какими-либо действиями правительства США, происходили самые настоящие баталии между рабочими и их работодателями и даже правительственными войсками. В 1893 году началась одна из самых известных экономических депрессий и, как следствие, люди вышли на улицы агитировать правительство помочь им. В итоге все вылилось в столкновение, в котором принимали участие безработные под предводительством Джекоба Кокси («Армия Кокси») и правительственные войска [2, с. 286]. Президент Гловер Кливленд отреагировал на это следующим образом: «...Народу надлежит проявлять патриотизм и готовность поддержать свое правительство, тогда как в функции правительства вовсе не входит оказание помощи народу» (Цит. по: [3, с. 336]).

В следующем году произошла знаменитая Пульмановская стачка, в которой соперничали рабочие и профсоюзные движения с одной стороны и железнодорожные компании - с другой. Причиной столкновения стало уменьшение зарплаты рабочих. В данной ситуации Г. Кливленд высказался аналогичным об- разом и в обращении к Конгрессу указал на то, что президент вправе использовать военную силу для подавления восстаний подобного рода [4, p. 79-121]. В итоге все закончилось разгоном многотысячной толпы посредством правительственных вооруженных сил. «...С ростом промышленности после Гражданской войны массовые конфронтации между мощными трудовыми фракциями и капиталом стали обычным явлением. Между 1870 и 1920 гг. происходили столкновения в различных отраслях промышленности между рабочими и работодателями: в железнодорожной сфере в 1877, 1886, 1894 и 1911; в угледобывающей сфере и рудных шахтах через каждые 10 лет; в некоторых сферах постоянно, а в железодобывающей и сталелитейной промышленности несколько раз, особенно в Гомстеде в 1892 и Гэри - в 1919 г.» [5, р. 467]. Данные события можно считать свидетельством низкого уровня жизни большинства населения страны, серьезного расслоения американского общества, а также четко сформулированной политики американского правительства, которое не вмешивалось в выяснение отношений бизнеса и рабочих, а лишь наводило общественный порядок силой по мере нужды.

«Десять процентов семей владели тремя четвертями всего национального достояния страны», - отметили советские ученые [1, с. 14]. Социальное расслоение населения Соединенных Штатов Америки, роль «ночного сторожа», которую играло государство, были закономерным явлением, если обратиться к доминирующей идеологии, которая формировала внутреннюю и внешнюю политику того времени.

В одном из журналов того времени - Harper's Weekly - можно было найти статью об одном из инициаторов кровавого столкновения в упомянутом выше Гомстеде в 1892 году. В ней мы можем увидеть подробнейший рассказ о том, как мультимиллионер Генри Клей Фрик проявил себя настоящим героем в борьбе с напавшим на него убийцей. Покушение на такого видного для США человека достойно подробнейшего обзора, но те детали, которые нам предлагает автор, и подача материала наполнены художественными преувеличениями. Автор статьи в подробностях рассказывает о том, как в Г.К. Фрика дважды стрелял преступник, и оба выстрела пришлись в область шеи. После подобного Фрику повезло выжить, но далее статья повествует о невероятной схватке. Генри Фрику пришли на помощь, но он нашел в себе силы встать и вступить в борьбу с неприятелем, помогая своему заместителю мистеру Лейшману. В пылу борьбы у нападавшего появился нож и им он ударил Г. Фрика семь раз в ногу! Но и на этом чудеса стойкости и благородства не заканчиваются. Когда в кабинет прибежали подчиненные с оружием, и заместитель шерифа мистер Мэй, Генри Фрик предотвратил убийство нападавшего, произнеся: «Не стреляйте! Не убивайте его! Закон накажет его» [6, р. 749-750]. Удивительная история героизма, если только не быть знакомым с биографией одного из самых расчетливых и жестоких бизнесменов того времени. Газеты пытались смягчить и даже преобразить образ финансиста за счет таких статей, на наш взгляд, в самых низших слоях американского общества - в массах. Подобный героизм Генри Фрика, на наш взгляд, не случаен. Он прекрасно укладывается в логику социал-дарвинистских идей о превосходстве американских элит, прежде всего имеется в виду 
политическая и экономическая элиты, над остальной частью населения. Но для интеллектуальных элит существовали и более серьезные авторские работы, например, его коллеги по бизнесу Эндрю Карнеги.

Одним из ярчайших представителей экономической элиты, который активно участвовал в формировании идеологического дискурса, был Эндрю Карнеги - один из крупнейших бизнесменов того времени, чье имя не забыто и сегодня благодаря активной благотворительности. Карнеги не только помогал библиотекам и университетам, будучи основателем одноименного фонда, но и сам занимался писательским ремеслом. Его писательский талант распространялся на самые насущные проблемы своего времени во внутренних делах США и даже на внешнюю политику. Самой известной работой Э. Карнеги стала статья «Богатство», написанная им в 1889 году. В этой статье американский бизнесмен говорил о том, что контраст между миллионером и рабочим нужно воспринимать как явление позитивное, положительно раскрывающее процесс «прогресса человеческого рода». «Всеобщее убожество» - альтернатива, по мнению автора статьи, тому положению вещей, которое укоренилось в американском обществе. Возврат в прошлое, к всеобщему равенству, «разрушителен для современной цивилизации, и никто не в силах изменить что-либо», - пишет Карнеги [7, p. 2]. Этот эволюционный подход к событиям прошлого и настоящего был продолжен рассуждениями автора о том, что современные рабочие имеют больше экономических благ, чем фермеры прошлого. Фермеры, в свою очередь, живут лучше, чем их хозяева земли, а арендодатели пользуются благами, о которых не могли мечтать и короли прошлого [7, р. 3]. Далее автор критикует эгалитарные устремления общества, называя эти идеи революционными. «Это требует изменения человеческой природы - пишет Карнеги, - что потребует столетий» [7, p. 7]. Естественный, эволюционный процесс развития, с какими бы издержками для общества в целом он ни проходил, не должен нарушаться. Этот подход копирует идеи Герберта Спенсера, который был довольно популярен в Соединенных Штатах в те годы. «...Рост общества по его постепенности напоминает нам рост живых существ», - писал Г. Спенсер [8, с. 288]. Следовательно, общество - организм, который растет и развивается подобно животному, и революционные скачки в его развитии недопустимы. Вмешательство правительства может только навредить эволюционному, естественному процессу развития общества. Спенсер писал по этому поводу следующее: «Думают, что чиновник будет действовать именно так, как от него ожидают... а этого в действительности никогда не бывает. Коммунистический механизм... придется строить из материала, какой имеется налицо в свойствах человеческой природы, а недостатки... последней породят... бедствия... властолюбие, эгоизм, несправедливость, недобросовестность...» [9, с. 78]. Похоже, что совокупность этих идей сформировали основные пассажи Эндрю Карнеги в статье «Богатство». Антропологический пессимизм в отношении людской природы, эволюционный подход без вмешательства человека, который своими врожденными недостатками и благими намерениями устроит «социальный ад».

Конкуренция и индивидуализм, по мнению Э. Карнеги, являются слагаемыми успеха американского общества. Они являются залогом «выживания сильнейших» в обществе. «Поэтому мы приветствуем... социальное неравенство, к которому мы должны приспособиться... концентрацию деловой, промышленной и коммерческой деятельности в руках немногих... это полезно и важно для будущего прогресса расы» [7, p. 4].

Социал-дарвинистская риторика заключается в использовании определенных концептов, которые придают ярко выраженную идеологическую направленность политическим текстам, выступлениям. Индивидуализм и свободную от государственного регулирования рыночную экономику США подкреплял мощнейший идеологический дискурс, выражавшийся в решающем значении таких понятий, как «борьба за выживание», «естественный отбор», «выживание сильнейших», «прогресс расы» и многих других. Общий смысл риторики заключался в том, что социально-экономическое неравенство, отсутствие социального законодательства является результатом общественной эволюции, и прерывать ее означало навредить всему обществу.

Государственная политика в социально-экономической сфере в основном следовала тем курсом, о котором писал сталелитейный магнат Карнеги. В 1875 году в Нью-Джерси появлялись законы, согласно которым крупные корпорации могли рассчитывать на существенные льготы перед кредиторами и рассчитывать на другие дополнительные преференции в ведении бизнеса. В 1899 г. еще более выгодные условия для крупного бизнеса предоставил штат Дэлавер, далее конкуренция между штатами по предоставлению лучших условий только возрастала в надежде заполучить крупного налогоплательщика [10, с. 38-39]. В 1887 году президент Кливленд отказал в период засухи в помощи фермерам, аргументировав тем, что «в таких случаях федеральная помощь... поощряет ожидания отеческой заботы со стороны правительства и ослабляет наш крепкий национальный характер». Хотя в том же году использовал излишки золотого запаса для выплаты держателям облигаций стоимостью 45 млн долларов (цит. по: [2, с. 285]). В 1895 году тот же Гровер Кливленд пополнил золотой государственный запас за счет обмена государственных облигаций на золото крупных предпринимателей. Последние перепродали их и выручили 18 миллионов долларов [2, с. 282].

Конец XIX века также ознаменован законодательством, которое должно было снять социальную напряженность и помочь сделать первые шаги на пути к социальной справедливости. В 1887 году был принят «Закон о торговле между штатами», который должен был устранить сговор монополий по цене на грузоперевозки, разорявшие фермеров и мелких предпринимателей. Однако закон не работал в полной мере и оказался некоторым компромиссом, который не ущемлял интересов крупного бизнеса (см., н-р: [1, c. 45-46; 2, с. 285]). В 1890 году был принят знаменитый «Закон Шермана», согласно которому монополии объявлялись незаконными. Однако и этот закон не работал против крупного бизнеса, а иногда суды интерпретировали его против, например, профсоюзов $[1$, с. 46]. Верховный суд трактовал новое законодательство таким образом, что монополии чувствовали себя в безопасности, как и прежде. Очень любопытны слова члена Верховного суда Дэвида Дж. Брюэра по поводу данного законодательства:

Самарский научный вестник. 2019. Т. 8, № 4 (29) 
«Является неизменным законом то, что благосостояние общества будет находиться в руках немногих. ...Огромное большинство людей не желает выносить длительного самопожертвования и бережливости, которое делают возможным накопление средств... а посему, если не изменится природа человека, всегда было и будет так, что богатство страны находится в руках немногих, а остальные должны положиться на плоды своего повседневного тяжкого труда» [2, с. 288].

Законодательство, которое формально можно назвать социальным, не работало по причине вольной интерпретации законов Верховным судом. Члены Верховного суда, подобно Д.Дж. Брюэру, трактовали законодательство в пользу монополий. Причинами этому были экономические интересы и политико-идеологические устои американского общества конца XIX в. Брюэр апеллирует к «природе человека», естественной стратификации общества, естественной эволюции, естественному отбору. Благосостояние находится в руках немногих, потому что только они этого заслуживают по принципу естественного отбора.

Особо выделить стоит законодательство по поводу тарифов на ввоз импорта. Согласно логике, которую избрало правительство и крупный бизнес во взаимоотношениях с рабочими, фермерами и др., было бы справедливо предположить, что протекционистские тарифы на ввоз товаров выглядели бы неразумно и вмешательство государства в этой связи стало бы разрушительно по отношению к «естественному» процессу развития всего общества. Однако конец XIX - начало XX века было ознаменовано мощными протекционистскими барьерами для импорта в Соединенные Штаты Америки.

Апогеем повышения пошлин на ввоз зарубежных товаров стали 1890-е гг. В 1890 году был одобрен законопроект «Маккинли-Олдрича», по которому тарифы поднимались до рекордной отметки в 49,5 процентов. В 1894 г. пошлины были снижены до 39,5, но в 1897 г. пошлины вновь установили рекорд, достигнув 57 процентов [1, с. 51-52]. Подобная политика, на наш взгляд, противоречила общепринятому в данный период постулату свободного от вмешательства правительства экономического развития. Две политические партии США разделялись по принципу поддержки протекционизма и его критики. Республиканская партия поддерживала протекционистские ввозные пошлины, демократы критиковали их. Но так как политический перевес после Гражданской войны преимущественно был на стороне республиканцев, то и политика в области тарифов была соответствующей.

Один из авторитетнейших американских ученых конца XIX века Уильям Самнер видел в этом противоречии политики США угрозу нормальному развитию американского общества. Американский социолог говорит о том, что критика свободной конкуренции, даже подкрепленная аргументами из области морали, не работает и протекционизм является негативным инструментом в руках правительства. «Капитал - это первое необходимое условие разного рода человеческих благ, следовательно, увеличение капитала - расширение возможностей, которые могут принести интеллектуальные, моральные и духовные блага». Если же протекционистские тарифы уменьшают капитал, то и шансы на осуществление всевозможных благ снижаются [11, p. 143-144]. «Протек- ционизм совершенно неосуществим... он не дает тех результатов, что были обещаны...» [11, p. 137-138]. Критика тарифной политики правительства со стороны одного из известнейших и влиятельных американских профессоров лишь укрепляет нашу мысль о противоречии идеологического дискурса и реальной внутренней политики. Это, на наш взгляд, один из первых шагов в сторону регулируемой государством экономической политики, которая станет актуальной в XX веке, но инициатива в подобных решениях в XIX веке принадлежала по большей части самому бизнесу, а не правительству.

Еще одним важным звеном политики государства, способствующим формированию необходимого для правительства США мировоззрения, является сфера образования.

Президент Кливленд в 1896 году произнес речь в честь 150-летия с момента основания Пристонского университета. В этой праздничной речи говорится о том, что выпускники высших учебных заведений должны «сыграть важную патриотическую службу» для американского общества, «в обеспечении соблюдения непреложных истин и основополагающих принципов, которые связаны с нашим национальным состоянием». Далее Гровер Кливленд говорил о том, что он надеется на помощь американских университетов и колледжей, когда народное недовольство достигнет своего апогея. Кроме того, президент добавил, что если кто-то захочет «ввести людей в заблуждение относительно того, что их страдания могут изменить действие естественных законов... я хотел бы, чтобы наши университеты и колледжи провозгласили, что эти законы неумолимы и далеки от политического контроля... я уверен, что более постоянное и активное участие в политической жизни наших воспитанников будет иметь для нашей страны как можно большую ценность» [12, p. 6-7]. Г. Кливленд, таким образом, перед выпускниками и одним из престижных учебных заведений страны ставил задачу поддержания установившегося политико-экономического порядка, называя его «естественным». Призывая к патриотизму, президент поддерживал существовавший в обществе социал-дарвинистский идеологический дискурс.

Немаловажным являлось и то, что многие крупные учебные заведения были открыты и финансировались за счет крупных предпринимателей. Такие бизнесмены, как К. Вандербилт, Э. Корнелл, Д. Дьюк, Л. Стенфорд, были основателями всеми известных и сегодня университетов, а Дж. Рокфеллер, Э. Карнеги, К.П. Хантингтон вкладывали довольно большие суммы в развитие колледжей и университетов по всей стране [2, с. 289].

Крупнейшие умы университетов Соединенных Штатов также способствовали воспитанию интеллигенции с тем образом мышления, который президент Кливленд называл «патриотическим». Уильям Грэм Самнер, профессор Йельского университета, был сторонником идеи свободного от вмешательства государства предпринимательства, также поддерживал концепцию экстраполяции законов биологии на социальную действительность, разделял взгляды Спенсера по поводу пользы «борьбы за существование» и «естественного отбора» в обществе. «Опасность заниматься чужими делами - проблема двоякая: вопервых, есть опасность оставить свои дела без должного присмотра; во-вторых, это негативное вмеша- 
тельство в чужие дела», - пишет Самнер. По мысли автора, так как лучше нас самих никто не знает наших потребностей, вмешательство государства недопустимо [13, p. 99-100]. Свободная от вмешательства государства экономическая политика - самая эффективная и разумная, по мнению Самнера, также она не нарушает естественный ход развития общества, который тождественен развитию живого организма. «Тяготы повседневной жизни - естественны. Они - часть борьбы с природой за существование... если мой сосед преуспел в этой борьбе лучше меня, это не составляет никакой обиды... Различия между бедами, которые относятся к борьбе за существование, и теми, что обусловлены недостатками человеческих институтов, имеют первостепенное значение... первый класс бед должен быть встречен мужественным усилием...» Второй класс бед, по его мнению, предполагает вмешательство одной социальной группы в жизнь другой, а это недопустимо, потому что одни и те же методы борьбы с неприятностями, по мысли автора, не могут быть применены для разных социальных групп [13, р. 17]. Социальный дарвинизм У. Самнера очень органично сочетается с социально-экономической политикой государства, и, без сомнения, он был взят на вооружение экономической и политической элитой США конца XIX века. «Человек в свободном состоянии не может требовать помощи от другого и не может быть обязан оказывать помощь другому» - эти слова представляют ярко выраженную приверженность индивидуализму не только в области экономической деятельности, но и в повседневной жизни, составляя тем самым важную часть мировоззрения определенной части американского общества [13, p. 24].

Еще одним популярным американским ученым, который при интерпретации различных исторических сюжетов воспользовался идеями Чарльза Дарвина и Герберта Спенсера, был Джон Фиске. Этот историк работал в таких крупных университетах, как Гарвардский университет, Королевский институт Великобритании и других. Фиске являлся сторонником эволюционного развития общества. «Правительство Соединенных Штатов не является результатом особого творения, но эволюции», - отмечал Фиске $[14$, p. 4]. Эволюция общества в работах Фиске тесно связана с расистской теорией, которая была популярна в США конца XIX века и являлась частью комплекса социал-дарвинистских идей. «...Две великие ветви английской расы имеют общую миссию создания более высокой цивилизации на еще большей части земли, чем это было прежде...» [14, р. 6]. Таким образом, Дж. Фиске отмечает, что будущее принадлежит англосаксонской расе, а «...такие страны, как Франция и Германия, могут претендовать на такое относительное положение в политическом миpe, как Швейцария... их величие в мысли и науке, в промышленности, искусстве, несомненно, будет продолжаться», - пишет американский историк, но главную роль в развитии мирового сообщества будут играть англичане и американцы [14, p. 137-138].

Чарльз Хортон Кули, президент Американской ассоциации социологов, посвятивший в «Америкэн джорнал оф сошиолоджи» статью о Герберте Спенсере в 1920 году, писал о том, что почти все ученые, которые занимались социологией в период между 1870 и 1890 годами, говорили, что делали это под вдохновением творчества Г. Спенсера. А количество книг английского ученого, изданных в США, доходило почти до четырех сотен тысяч [15, p. 33-34]. При этом социал-дарвинистским дискурсом пользовались как сторонники, так и критики социалдарвинистской политико-экономической модели.

Одним из критиков социал-дарвинизма, который впоследствии стал ярчайшим представителем американской социологии своего поколения, был Лестер Уорд. Социология Л. Уорда была, как он сам ее называл, «прикладной», и «... с точки зрения прикладной социологии все люди равны... прикладная социология эгалитарна в той мере, в какой она направлена на обеспечение этого права для всех людей...» [16, р.7]. Уорд предлагал реформировать общественные институты, которые не приносили ожидаемой пользы посредством «сознательных действий общества» и тем самым сделать общество более справедливым и стабильным. Эти действия, на наш взгляд, были синонимом правительственного вмешательства в социальную материю государства, которую так оберегал, например, У. Самнер и которая должна была развиваться без вмешательства правительства [16, p. 5]. Лестер Уорд активно оппонировал тем самым социал-дарвинистским воззрениям, которые у него ассоциировались с работами Герберта Спенсера. Социолог, который берется анализировать текущее состояние вещей в обществе, рискует стать политиком, по мнению Уорда. Именно так американский социолог и характеризует Спенсера. Даже в «Синтетической философии» «... многое отражает его предрассудки и его эмоции и не является научным», - пишет Л. Уорд. Здесь же Уорд критикует и социалистов, которые стремятся изменить общество более радикально, чем это возможно на деле, по его мнению [16, p. 10-11]. Важно то, что Лестер Уорд, критикуя политиков, общественных деятелей и ученых, которые представляли доминирующую тогда идею невмешательства правительства в экономику, политику laissez-faire, использует общепринятые в то время понятия социал-дарвинистской риторики, например, понятие «раса». При этом речь идет о роли государства в социальной политике. «Цивилизованные расы... в состоянии абсолютной летаргии в отношении социальных вопросов... человеческая раса нуждается в пробуждении и осознании своего состояния», - пишет Уорд [16, p. 21]. Кроме того, «нет такой расы или класса, которые не в состоянии усвоить социальные достижения человечества...» [16, p. 110].

Социолог признает естественное неравенство возможностей индивидов, но оно должно, по мнению Уорда, сглаживаться «искусственным отбором». Цивилизованное общество двигалось по пути вмешательства в «естественный отбор» и эксплуатацию слабых сильнейшими, по мнению Л. Уорда, в сторону развития гражданского, политического, правового равенства и справедливости от «закона природы» к искусственным социальным институтам. «Проблема заключается в том, как обеспечить членам общества максимальную способность осуществлять свои естественные способности. ... Проблема... не имеет ничего общего с относительным превосходством или неполноценностью людей. ... Не зависит от вопроса их интеллекта или социальной ценности... важно лишь то, чтобы они могли пользоваться теми способностями, которыми они могут обладать» [16, p. 23, 25-26]. 
Таким образом, социал-дарвинистский дискурс был основной точкой отсчета в исследованиях как апологетов в академической сфере социально-экономической политики, так и ее критиков. Сторонники социального дарвинизма критикуют вмешательство в естественный ход вещей. «Искусственный отбор», по их мнению, только мешает нормальному развитию общества. Конкуренция приводит к успеху только сильнейших, следовательно, «искусственный отбор приведет только к негативным последствиям в разных сферах жизнедеятельности общества из-за некомпетентной работы «худших» индивидов. Следует отметить, Лестеру Уорду в своих работах, оппонируя Герберту Спенсеру и Уильяму Самнеру, не удается выйти из пространства социал-дарвинистского дискурса. Уорд сделал значительный шаг к формированию идей «буржуазного реформизма», так традиционно советские и российские ученые называют период реформ в США начала XX века. Важно отметить, что его интеллектуальные усилия были направлены против доминирующей в то время социал-дарвинистской идеологии. Также важно выделить то, что в период своей публикации работы Л. Уорда не имели особой популярности и значительных дискуссий в академической среде не вызвали $[15$, p. 70$]$.

Язык, которым индивид пользуется в обыденной жизни, в академической среде, политике и т.д., формирует наше мировоззрение, влияет на принятие решений на практике. Социал-дарвинистская идеология определяет доминирующий на рубеже XIX$\mathrm{XX}$ вв. в политике, экономике, интеллектуальной среде дискурс. Представления финансистов, экономистов, социологов, политиков, принимавших в данный исторический период непосредственные решения на самом высоком уровне, были продиктованы или оправдывались тем, что мы называем социалдарвинистскими идеями. Эти решения, выраженные в законодательстве, в судебных решениях, аргументации по поводу отсутствия принятых мер в социальной политике под влиянием социал-дарвинизма, выглядят бескомпромиссными и жестокими. Но если разобраться в комплексе этих идей, то внутренняя политика США не кажется безосновательной, безрассудно хищнической. Она обоснована интеллектуально и базируется на мощнейшем авторитете не только американских академических кругов, но и на трудах английских всемирно известных ученых Герберта Спенсера и Чарльза Дарвина. Ч. Дарвин был человеком, который мотивировал на интеллектуальные подвиги многих авторов в то время в Европе и США, экстраполировавших последние достиже- ния биологии на социальную действительность, а Г. Спенсер стал главным авторитетом в области социальных наук в Соединенных Штатах Америки в конце XIX века. Это не могло не затронуть и не сказаться на внутренней политике американского общества рубежа XIX-XX вв.

\section{Список литературы:}

1. История США. Т. 2 / под ред. Г.Н. Севостьянова М.: Наука, 1985. 599 с.

2. Зинн Г. Американская империя. С 1492 года до наших дней. М.: Алгоритм, 2014. 752 с.

3. Шлезингер А. Циклы американской истории. М.: Прогресc, 1992. 688 c.

4. Cleveland G. Presidential Problems. New York. The Century CO. 1904. $281 \mathrm{p}$.

5. Jeffreys-Jones R. Violence in American History: Plug Uglies in the Progressive Era / Perspectives in American History; Editors Donald Fleming and Bernard Bailyn. Vol. VIII. 1974. 583 p.

6. Chamberlin W.J. The assault on Mr. Frick // Harper's Weekly. Journal of Civilization. New York: Saturday, August 6, 1892. P. 749-750.

7. Carnegie A. The Gospel of Wealth and Other Timely Essays. New York: The Century CO, 1900 $305 \mathrm{p}$.

8. Спенсер Г. Основания социологии: Данные социологии. Индукция социологии. Пер. с англ. Изд. 3 е. М.: Книжный дом «Либроком», 2013. 440 с.

9. Спенсер Г. Личность и государство / пер. с англ. Челябинск: Социум, 2006. 205 с.

10. Мозолин В.П. Корпорации, монополии и право в США. М.: Издательство Московского государственного университета, 1966. 398 с.

11. Samner W.G. Protectionism. The ism wich teaches that waste makes wealth. Henry Holt and Company. New York, 1883. $172 \mathrm{p}$.

12. Cleveland G. Speech at Princenton's Sesquicentennial Celebration. Washington, $1896.8 \mathrm{p}$.

13. Samner W.G. What Social Classes Owe to Each Other. Caldwell, Idaho: The Caxton Printers, Ltd., 1974. $145 \mathrm{p}$.

14. Fiske J. American Political Ideas. Boston and New York Hough Mifflin Company. 1911. 196 p.

15. Hofstadter R. Social Darwinism in American Thought. Beacon Press Boston. 1992. 248 p.

16. Ward L.F. Applied Sociology. A Treatise on the conscious improvement of society by society. Ginn and company. Boston, 1906. 384 p.

\section{THE SOCIAL DARWINIST IDEOLOGY IN AMERICAN DOMESTIC POLICY AT THE TURN OF THE XIX-XX CENTURIES}

(C) 2019

Mukhataev Pavel Nikolaevich, teacher of history and social theory Gymnasium № 133 of Samara Urban Okrug (Samara, Russian Federation)

\footnotetext{
Abstract. This paper presents an attempt to analyze the interrelation between American domestic policy and the Social Darwinist ideology at the turn of the XIX-XX centuries. Soviet and Russian historiography presents a deep analysis of socio-economic and political processes in that period in terms of criticism of liberal ideology and market economics. Significant social stratification was explained by insufficiently developed socially directed normative base, illegal interaction between representatives of large business and politicians, the purpose of which was personal enrichment, etc. In general, the economic and political system of the United States in the late XIX - early XX centuries was criticized from Russian scientists. In Soviet literature the conclusion was made about the insolvency of «bourgeois ideology», with elements of criticism of Social Darwinism as a minor component of this ideology. American historiography considers the subject of our study more wholly. Foreign historiography, basically, analyzes the
} 
connection of American domestic policy with the activities of financial magnates, who were becoming a new serious power in American politics. This paper attempts to explain the connection between the American domestic policy and the Social Darwinist discourse, which was an undoubted part of the intellectual and daily life of citizens in that historical period. The author points to the significant influence of the Social Darwinist ideology in the adoption of key inner-political decisions by the government of the United States.

Keywords: Social Darwinism; American domestic policy turn of XIX-XX centuries; G. Spenser; A. Carnegie; L.F. Ward.; W.G. Samner; G. Cleveland; J. Fiske; H. Zinn; V.P. Mozolin; natural law; K. Frick; A. Schlezinger; J. Brewer; C. Cooley; protectionist policy; R. Hofstadter; laissez-faire.

$* * *$

\title{
БЫТОВЫЕ ТЕМЫ В САТИРЕ ДЛЯ ЛЮБИТЕЛЕЙ НОВОСТЕЙ: ВОЗМОЖНОСТИ АДАПТАЦИОННОГО РЕСУРСА (ПО МАТЕРИАЛАМ ПЕРИОДИЧЕСКОЙ ПЕЧАТИ ПОВОЛЖСКИХ ГОРОДОВ В ГОДЫ ПЕРВОЙ МИРОВОЙ ВОЙНЫ)
} (C) 2019

\author{
Семенова Екатерина Юрьевна, доктор исторических наук, доцент, \\ заведующий кафедрой социологии, политологии и истории Отечества \\ Самарский государственный технический университет (2. Самара, Российская Федерачия)
}

Аннотация. В статье исследуются возможности сатирических материалов в качестве механизма адаптации тылового населения к повседневным условиям жизни. Выявлены темы бытовой сатиры, получившие развитие в печатной продукции, выпускавшейся в годы Первой мировой войны на территории городов Поволжья. Они представлены в единичных сатирических изданиях, а также в неофициальной периодической печати, в изданиях политических партий и официальных органов власти. Автор проанализировал материалы, включающие бытовую сатиру, по следующим направлениям: обеспечение населения тыловых городов, борьба с пьянством, использование войны в целях наживы, социальные конфликты, устойчивость внутриполитического курса, досуговые возможности. Выявлено, что в периодике, выходившей на территории городов Поволжья, сатирические материалы были представлены рядом жанров: частушкой, фельетоном, пословицей, пародией - в литературной форме прозы и стиха. Автор пришел к выводу о значимости сатирических материалов для отражения повседневных проблем, с которыми сталкивался городской обыватель. Подчеркивая, что источниковая база является косвенной, предложено учитывать возможности влияния сатиры на привыкание горожан, читающих периодику, к бытовым проблемам, связанным с войной.

Ключевые слова: сатирические материалы; периодическая печать; региональные газеты; Поволжье; российская провинция; тыловой город; Первая мировая война; фельетон; частушка; пародия; пословицы военных лет; военная повседневность; быт; психологическая адаптация; механизмы привыкания.

Жизнь горожанина тыловой российской провинции в годы Первой мировой войны отличалась рядом новаций, постепенно ставших повседневными. Они затронули бытовую сферу, включали разнообразные социально значимые практики - благотворительную деятельность в пользу раненых и больных воинов, беженцев, малоимущих учащихся, коллег по профессиональной сфере, просветительскую работу; проблемные аспекты - очереди за продовольственными товарами, прежде всего за сахаром, мукой, мясом, соприкосновение с мобилизацией в действующую армию; новостное информационное поле, значимой частью которого являлись военно-политические события текущей войны.

В данных обстоятельствах обществу был необходим компенсаторный механизм, позволяющий выжить в сложный исторический период. Исследователи выявили разнообразие таких ресурсов, каждый из которых выполнял определенную роль в адаптации обывателя к сложившейся действительности.

В разработке данного направления была учтена фронтовая специфика. Так, Е.С. Сенявская отмечает, что условия фронта вырабатывали такие качества, как инициативность, находчивость, смекалку, способность принимать самостоятельные решения в сложной ситуации, составляли образ исполнителя, привыкшего к подчинению и четкому распорядку, к казенному обеспечению всем необходимым, и одновременно определяли становление сильного, независимого характера, волевой личности, способной принимать решения, руководствуясь реальной обстановкой и собственным боевым опытом, исходя из личного выбора и осознания собственной значимости [1]. По мнению Я.В. Валяева, значимую роль в адаптации к экстремальным условиям фронта для российских военнослужащих играли переписка с родственниками и возможности развлекательного досуга [2, с. 23]. В.Л. Кожевин акцентировал внимание на особенностях адаптации в связи с социальным статусом, пришел к выводу о том, что для офицеров на фронте основной комплекс ценностных установок довоенного периода сохранял свое определяющее значение в отношении всего офицерского сообщества и служил важнейшим ориентиром [3, с. 18].

Авторы выявили особенности адаптации в условиях войны тылового населения. О.С. Нагорная полагает, что совместная работа и бытовые контакты заставили в годы Первой мировой войны население в тылу, для которого пленные были единственным живым воплощением врага, частично пересмотреть пропагандистские стереотипы и наладить нормальные человеческие отношения с военнопленными [4, 